\title{
Preparation of Polyimides by Using Mixtures of Tetrahydrofuran and Methanol and Their Properties
}

\author{
Petr SySEL,$^{\dagger}$ Vladimír ŠINDELÁŘ, Eliška CHÁNOVÁ, and Birgitta WALLIN* \\ Department of Polymers, Institute of Chemical Technology, 16628 Prague 6, Czech Republic \\ *Department of Physical Chemistry, Goteborg University, 41296 Goteborg, Sweden
}

(Received April 23, 2001; Accepted October 30, 2001)

\begin{abstract}
Reaction conditions of the preparation of solutions of polyamic acids in the tetrahydrofuran/methanol mixed solvent (THF/MeOH) were studied. The polyamic acids were based on pyromellitic dianhydride and 4, 4'oxydianiline. Transparent solutions were prepared at $5 \mathrm{wt} \%$ and lower concentrations of polyamic acid in the $\mathrm{THF} / \mathrm{MeOH}$ mixture with component weight ratio ranging from 4:1 to 1:1. The properties of the final polyimide films were compared with those prepared by using $N$-methyl-2-pyrrolidone as the solvent.
\end{abstract}

KEY WORDS Methanol / Polyamic Acid / Polyimide / Tetrahydrofuran /

Aromatic polyimides (PI) exhibit very good mechanical, dielectric and chemical resistance also at elevated temperatures. They are often employed in (micro)electronics, aviation industry and membrane technologies. ${ }^{1}$

Polyimides are traditionally synthesized in two steps (Figure 1). The final product is often prepared by thermal solid-state imidization of a polyimide precursor (polyamic acid (PAA)). ${ }^{1}$ The first step - preparation of PAA - comprises the reaction of an aromatic diamine with an aromatic dianhydride in aprotic polar solvents (e.g., $\mathrm{N}$-methyl-2-pyrrolidone (NMP), $\mathrm{N}, \mathrm{N}$ dimethylacetamide, $N, N$-dimethylformamide). These amidic high-boiling solvents however associate with the carboxyl groups of PAA and removing them from polyimide films can be troublesome. ${ }^{1}$ Moreover, polyamic acid solutions in these hygroscopic solvents are unstable and their application using the spin-on technique can be thus complicated. ${ }^{2}$

From this point of view the preparation of PAA in the

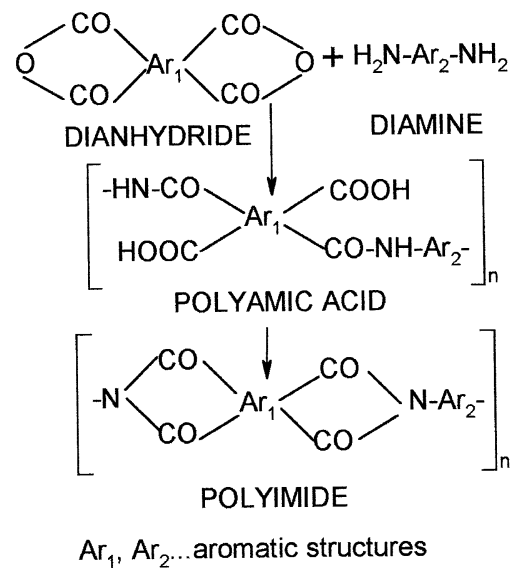

Figure 1. Two-step synthesis of polyimides.

${ }^{\dagger}$ To whom correspondence should be addressed. tetrahydrofuran/methanol mixed solvent (THF/MeOH) appears to be promising. ${ }^{3-8}$ However, in our preliminary tests we were unable to reproduce the preparation of $15 \mathrm{wt} \%$ solutions of PAA based on pyromellitic dianhydride (PMDA) and 4, 4' -oxydianiline (ODA) in $\mathrm{THF} / \mathrm{MeOH}$ with component ratio $4: 1(\mathrm{w} / \mathrm{w})$ as described by Echigo et al. . $^{3,4}$

The reaction conditions of the preparation of PAA solutions (based on PMDA and ODA) in THF/MeOH mixtures and the transformation of the resulting PAA into PI are studied in this work. The properties of final films are compared with those prepared by using NMP as the solvent. The behaviour of the mixed solvent in dependence on its composition has been monitored.

\section{EXPERIMENTAL}

Pyromellitic dianhydride was dried overnight at $180^{\circ} \mathrm{C}$ in vacuum before using. 4, 4'-Oxydianiline (both Aldrich) was used as received. Tetrahydrofuran (Lachema, Czech Republic) was distilled over sodium. Methanol (Penta, Czech Republic) was used without purification. $N$-Methyl-2-pyrrolidone (Merck) was distilled under vacuum over phosphorus pentoxide and stored under an inert gas.

Polyamic acids were prepared in a three-necked flask equipped with a mechanical stirrer, a nitrogen inlet, and a condenser with a drying tube. The diamine (ODA) was dissolved in the solvent (THF/MeOH or NMP). An equimolar amount of the dianhydride (PMDA) was then added and the reaction was allowed to proceed at room temperature for $24 \mathrm{~h}$.

A polyamic acid solution in $\mathrm{THF} / \mathrm{MeOH}$ or NMP was cast onto a glass plate and spread out with a casting knife. After drying at room temperature (THF/MeOH) or elevated temperature (NMP) the film was heated 
to gradually increasing temperatures, at last $330^{\circ} \mathrm{C}$ for $30 \mathrm{~min}$. The films, about 20 microns thick, were slightly opalescent.

Intrinsic viscosities of PAA were measured in NMP at $25^{\circ} \mathrm{C}$. IR spectra were taken with a NICOLET 740 spectrometer. Dynamic thermogravimetric measurements were performed in air with a DuPont 990 Thermal Analyzer, module 951 (heating rate $10^{\circ} \mathrm{C} \mathrm{min}^{-1}$ ). Tensile properties were measured with Instron 1122 at room temperature at a drawing rate of $20 \mathrm{~mm} \mathrm{~min}^{-1}$. Permeability coefficients were determined using an inhouse designed and built differential permeameter. ${ }^{9}$ The wide angle X-Ray diffraction (WAXD) measurements were performed with a VRON-UM-1 diffractometer with a $\mathrm{Cu}$ lamp (wavelength $0.154 \mathrm{~nm}$ ). The density of prepared films was determined pycnometrically. The kinematic viscosities of PAA solutions were measured using a capillary viscometer at $20 \pm 0.1^{\circ} \mathrm{C}$.

The kinematic viscosities of the mixed solvent of THF and $\mathrm{MeOH}$ at varying ratios of components were measured in the same manner. Their densities were determined pycnometrically.

\section{RESULTS AND DISCUSSION}

Pyromellitic dianhydride and 4, 4' -oxydianiline were the starting compounds for the synthesis of PI in this work. This combination of monomers is used in the manufacture of commercially successful PI Kapton (DuPont). ${ }^{1}$ These monomers were also frequently employed in studies devoted to PI synthesis using THF/MeOH mixed solvent. ${ }^{3-5}$

Concentrations of solutions of polyimide precursors (PAA) in NMP for commercial and research purposes usually range from 10 to $15 \mathrm{wt} \%$. Echigo ${ }^{3,4}$ describes the preparation of a $15 \mathrm{wt} \%$ PAA solution based on the above mentioned monomers using THF/MeOH mixtures with composition ratio 4:1 (w/w). During our polymerization tests PAA precipitated from the solution at concentrations higher than $5 \mathrm{wt} \%$ regardless of the THF/MeOH ratio of the two solvents. Transparent solutions were obtained at $5 \mathrm{wt} \%$ and lower PAA concentrations with the THF/MeOH ratio from 4:1 to 1:1. To obtain high-molecular-weight PAA it is necessary to dissolve a diamine in $\mathrm{THF} / \mathrm{MeOH}$ and then to add a dianhydride. ${ }^{6}$ We have found that it is possible to dissolve at the most $4 \mathrm{wt} \%$ of $4,4^{\prime}$-oxydianiline in $\mathrm{THF} / \mathrm{MeOH}$ mixtures with composition ratio ranging from $4: 1$ to $1: 1$ (Gaw $^{6}$ reported $3 \mathrm{wt} \%$ of $3,3^{\prime}$ oxydianiline in $\mathrm{THF} / \mathrm{MeOH}$ with composition ratio $4: 1)$.

A series of $5 \mathrm{wt} \%$ PAA solutions differing in the THF/MeOH composition $(4: 1,3: 1,2: 1,1: 1(\mathrm{w} / \mathrm{w}))$ was prepared. A portion of each solution was poured into water and the precipitate was dried to constant weight in a vacuum at room temperature. These PAA were characterized by their intrinsic viscosities. A broad maximum at around $30 \mathrm{~mL} \mathrm{~g}^{-1}$ was found for PAA prepared in $\mathrm{THF} / \mathrm{MeOH}$ with the weight ratio of components from 4:1 to 2:1. PAA prepared in $\mathrm{THF} / \mathrm{MeOH}$ with weight ratio of components 3:1 $[\mathrm{PAA}(\mathrm{THF} / \mathrm{MeOH})]$ was subsequently used. The intrinsic viscosity of $49 \mathrm{~mL} \mathrm{~g}^{-1}$ was obtained for PAA prepared in NMP [PAA(NMP)] under otherwise identical conditions.

The precipitated PAA dried in vaccum at room temperature to constant weight were analysed by TGA. We found that PAA(THF/MeOH) contains about 20 $\mathrm{wt} \%$ and PAA(NMP) about $40 \mathrm{wt} \%$ of low-molecularweight compounds (solvents and the precipitating agent). It is thus apparent that $\mathrm{PAA}(\mathrm{THF} / \mathrm{MeOH}) \mathrm{re}-$ tains these agents less tenaciously. Echigo ${ }^{4}$ showed that THF remains in PAA films even after drying at $80^{\circ} \mathrm{C}$ for $24 \mathrm{~h}$, while a major part of $\mathrm{MeOH}$ is evaporated upon drying at $40^{\circ} \mathrm{C}$ for $30 \mathrm{~min}$.

The kinematic viscosity of the PAA(THF/MeOH) solution measured immediately after its preparation was one order of magnitude lower $\left(3.25 \times 10^{-6} \mathrm{~m}^{2} \mathrm{~s}^{-1}\right)$ compared with the PAA(NMP) solution $\left(3.28 \times 10^{-5} \mathrm{~m}^{2}\right.$ $\left.\mathrm{s}^{-1}\right)$. The relative changes in kinematic viscosities after two-month storage at room temperature were comparable for both solutions (less than 10\%). In both cases the relative changes were reduced approximately to one half when the solutions were stored at $4^{\circ} \mathrm{C}$.

The kinematic viscosity of the $5 \mathrm{wt} \%$ PAA (THF/MeOH) solution is very low. It could bring about problems during potential application using the spin-on technique. We therefore increased the concentration of the PAA(THF/MeOH) solution by removing a part of the solvents in a rotary vacuum evaporator. The $10 \mathrm{wt} \% \mathrm{PAA}(\mathrm{THF} / \mathrm{MeOH})$ solution was sligtly turbid and its kinematic viscosity was $1.40 \times 10^{-5} \mathrm{~m}^{2} \mathrm{~s}^{-1}$. The $20 \mathrm{wt} \%$ PAA(THF/MeOH) solution was strongly turbid, but no phase separation took place. This is a very important finding for potential applications. To elucidate this phenomenon an analysis of the remaining mixed solvent (after a part was evaporated) will be necessary.

The extent of thermal imidization of PAA was monitored by IR spectroscopy. The spectra of the resulting PI were nearly identical regardless of whether the starting material was PAA(THF/MeOH) or PAA(NMP). The absorbance peak of the amide group at around $1650 \mathrm{~cm}^{-1}$ is very weak while the absorption at 1780 and $1720 \mathrm{~cm}^{-1}$ (symmetric and antisymmetric stretching of the imide ring carbonyl groups) and at 
Table I. Mechanical and Thermal Properties of the Prepared Polyimides

\begin{tabular}{lcc}
\hline Property & $\mathrm{PI}(\mathrm{THF} / \mathrm{MeOH})$ & $\mathrm{PI}(\mathrm{NMP})$ \\
\hline Tensile modulus $(\mathrm{GPa})$ & 1.5 & 1.6 \\
Tensile strength $(\mathrm{MPa})$ & 70.8 & 85.9 \\
Elongation $(\%)$ & 18.2 & 20.9 \\
$T^{\mathrm{a}}\left({ }^{\circ} \mathrm{C}\right)$ & 502 & 539 \\
\hline a & &
\end{tabular}

${ }^{\mathrm{a}}$ Temperature corresponding to $5 \mathrm{wt} \%$ loss.

Table II. Characterization of Polyimide Chain Packaging

\begin{tabular}{lcc}
\hline Property & $\mathrm{PI}(\mathrm{THF} / \mathrm{MeOH})$ & $\mathrm{PI}(\mathrm{NMP})$ \\
\hline Density $\left(\mathrm{g} \mathrm{cm}^{-3}\right)$ & 1.39 & 1.29 \\
$\mathrm{P}^{\mathrm{a}}\left(10^{17} \mathrm{~m}^{2} \mathrm{~Pa}^{-1} \mathrm{~s}^{-1}\right)$ & 3.56 & 3.63 \\
$\mathrm{~d}^{\mathrm{b}}(\mathrm{nm})$ & 0.50 & 0.55 \\
\hline \multicolumn{2}{c}{ Permeability coefficient for carbon dioxide. } & ${ }^{\mathrm{b}}$ Parameter d of \\
the Bragg equation.
\end{tabular}

$1370 \mathrm{~cm}^{-1}$ (stretching of the imide ring $\mathrm{C}-\mathrm{N}$ bond) is strong.

The thermal and mechanical properties of PI based on PAA (THF/MeOH) and PAA(NMP) are compared in Table I. The tensile modulus and strength and also the thermal stability are slightly higher for PI based on PAA (NMP). Echigo ${ }^{3}$ found the values of tensile modulus and strength $286 \mathrm{MPa}$ and $17 \mathrm{MPa}$, respectively. The properties characterizing the chain packing are compared in Table II. One may conclude from the values of densities, permeability coefficients for carbon dioxide and parameters $d$ of the Bragg equation that chain packing in PI based on PAA(THF/MeOH) is slightly higher.

Promising preliminary results were obtained when the $\mathrm{THF} / \mathrm{MeOH}$ mixed solvent was used for preparation of hybrid materials PI-silica by the sol-gel method. When NMP was used as the solvent self-standing films were prepared only up to $30 \mathrm{wt} \%$ silica content. By using THF/MeOH $(3: 1(\mathrm{w} / \mathrm{w}))$ the hybrid films were selfstanding up to $80 \mathrm{wt} \%$ silica content. The morphology and thermal and mechanical properties of these materials will be investigated. A THF/MeOH mixed solvent was used to prepare polyimide/clay hybrid films. ${ }^{10}$

The role of the THF/MeOH mixed solvent in the synthesis of PAA(THF/MeOH) is not clear. It was found, ${ }^{3}$ that the reaction of the pyromellitic acid dimethyl ester with ODA in THF/MeOH did not practically proceed. To elucidate this role -at least partly- the properties of mixed solvent were investigated in dependence on its composition. The densities of the mixed solvents followed almost exactly the theoretical values (calculated from densities of THF and $\mathrm{MeOH}$ and their content in the mixture). The dependence of the kinematic viscosity on the mixed solvent composition showed a broad minimum between $4: 1$ and 1:3 (w/w). The mixed solvents will be analysed by ${ }^{1} \mathrm{H}$ NMR presently.

\section{CONCLUSION}

Transparent solutions were obtained at maximally $5 \mathrm{wt} \%$ concentration of the PAA based on PMDA and ODA in the THF/MeOH mixture with component weight ratio ranging from $4: 1$ to $1: 1$.

For the $5 \mathrm{wt} \%$ PAA prepared in the THF/MeOH mixture with weight ratio of components 3:1 it was found:

1) By removing a part of the solvents the $10 \mathrm{wt} \%$ slightly turbid solution of the PAA(THF/MeOH) was obtained.

2) Chain packaging in PI based on PAA(THF/MeOH) was found to be slightly higher compared to PI based on PAA (NMP). On the contrary, the tensile modulus and strength and also the thermal stability were slightly lower.

3) $\mathrm{THF} / \mathrm{MeOH}$ mixtures were found to be promising for the preparation of self standing hybrid films PIsilica by the sol-gel process.

Acknowledgment. This work was supported by the Ministry of Education of the Czech Republic under grant CEZ:MSM 223100002 and by the grant of the Institute of Chemical Technology, Prague 112010016.

\section{REFERENCES}

1. C. E. Sroog, Prog. Polym. Sci., 16, 561 (1991).

2. J. M. Bureau, F. Bernard, and D. Broussoux, Revue Technique Thomson-CSF, 20-21, 689 (1989).

3. Y. Echigo, Y. Iwaya, I. Tomioka, M. Furukawa, and S. Okamoto, Macromolecules, 28, 3000 (1995).

4. Y. Echigo, Y. Iwaya, I. Tomioka, and H. Yamada, Macromolecules, 28, 4861 (1995).

5. Y. Echigo, Y. Iwaya, M. Saito, and I. Tomioka, Macromolecules, 28, 6684 (1995).

6. K. Gaw, H. Suzuki, M. Jikei, M. Kakimoto, and Y. Imai, Polym. J., 29, 290 (1997).

7. Y. Echigo, N. Miki, and I. Tomioka, J. Polym. Sci., Part A: Polym. Chem., 35, 2493 (1997).

8. K. Gaw, M. Jikei, M. Kakimoto, Y. Imai, and A. Mochjizuki, Polymer, 38, 4413 (1997).

9. P. Sysel, V. Hynek, and M. Šípek, Collect. Czech. Chem. Commun., 63, 53 (1998).

10. A. J. Gu and F. C. Chang, J. Appl. Polym. Sci., 79, 289 (2001). 